\section{Time Management}

\section{Valentijn Karemaker}

In spring 2020, I moved to the Netherlands to start a tenure-track position. At the same time as house-hunting during a semi-lockdown, I had to get settled at the university while working from home. In the subsequent months, while I tried to keep working on my research projects, I also started teaching an online course and supervising students, and joined some committees. With so many things to juggle in such strange circumstances, I often found myself a little overwhelmed by it all. I can imagine many of you have felt the same way. Below I will share my experiences on how to manage my time most effectively.

\section{Setting Goals}

It sounds obvious, but to plan what to spend your time on, it is crucial to first decide what you want to achieve. That is, you need to set goals for yourself.

Maybe you have heard of the slogan that goals need to be SMART (Specific, Measurable, Achievable, Relevant, and Time-bound). For me, this means that they should be concrete enough to write on a to-do list, with a clear deadline (set by yourself or by others), and that they can eventually be ticked off that to-do list. Some things may be too nebulous or too big to fit these criteria; they are either continuous (committee positions or seminar organization, for example), so vague that you don't know how to write them down, or so involved that you never feel you can cross them out. Nevertheless, you will often be able to extract small, SMART pieces.

Research is not SMART. You cannot write "Have a great idea" or "Understand this theory" on your to-do list. The only thing you can do there is decide what project(s) you want to work on, and allocate enough research time-more about that later.

In practice, at the start of every month I write a list of my goals for that month. These are numbered according to the week of the month I plan to do them in. Then at the start of each week, I make a new list containig the subset of that week's goals, and other things that may have come up (such as referee requests or follow-up actions from earlier goals). To these weekly goals, I then allocate a day of the week. In particularly busy weeks, I repeat the process to produce daily to-do lists. At the end of each day, week, and month, I go over the corresponding lists and tick off what I have done.

This may seem like a lot of list-writing, and in a way it is. (A friend of mine always jokes that the Dalton primary

Valentijn Karemaker is an assistant professor of mathematics at Utrecht University, the Netherlands. Her email address is V.Z. Karemaker@uu.n7.

DOI: https://dx.doi.org/10.1090/noti2272 school I went to, in which we always planned our own work, has ruined me forever.) But it gives a very good overview which allows you to schedule your time much more effectively. I think it is also important to not follow your lists blindly. Zoom out every now and then, and check whether your goals are realistic and sensible.

Sometimes it is difficult to predict how difficult or time-consuming a goal is. Some weeks you just have less energy. Adjust, don't just give up! Unexpected things happen, and that's ok. I try to schedule less at the end of the month (and week); this leaves more time for finishing things that I didn't manage to fit in before, or for recovery.

\section{Planning Your Week}

While working from home, it may feel that there is no real structure to any given day; so we will have to create that structure ourselves. Writing good to-do lists is already half the work-but only half. Once you have your lists of things you should be doing, how do you make sure that you actually get them done?

The next step (after list-writing) is prioritizing your tasks. I put the most weight on my research projects and correspondingly allocate the largest chunks of time to research. That is both because it is easy for me to keep doing smaller (teaching or service) things all day that have more immediate payoffs, and because it takes me a while to get into research mode, so smaller blocks of time would not lead to anything.

Having ordered your tasks by priority, you then allocate time to these tasks in order. For me, sometimes it is enough to only schedule time for the most important things. I still have my list of less important things on hand; there will always be a time before, between, or after other things where you'll have a few minutes to do those. Moreover, it doesn't help me to plan my whole day from minute to minute. Also, switching between tasks takes time and energy. And if something takes less time than expected, you can always write some emails (see below).

I think it makes sense to plan according to your strengths, i.e., to make sure your best time is free for your best work. The concept of "best time" is variable; mine is usually between 5 p.m. and 7 p.m. in summer and between 10 a.m. and noon in winter, so I keep at least these slots free for research time. The start or the end of the day is better for appointments with students or organizational meetings; this then also leaves the rest of the day free for other things.

How you end up planning your day is of course highly personal and depends on many factors. You will need to find your own strategies to get started, keep going, and wind down at the end of each working day. However, some general statements apply to everyone. First, stress levels are reduced by starting work early (whatever "early" means for you), so you will not feel "behind" all day. Second, having a routine will mean that you spend less energy on figuring out what to do when, and will therefore have more energy 
for the things you are actually doing. (If I'm enjoying my routine, I write it down, for inspiration in times where I feel less productive.) Third, after too long a working day, your productivity will be down the next day-so it's really not more efficient to work late (whatever "late" means for you).

\section{Emails}

Email is such a big thing that it deserves its own section. Writing emails is not a goal in itself, and you cannot plan when someone will write to you. Emails come in continuously and the more you write, the more you receive. In other words, you will never be done with email, but can only hope to stay on top of it, without spending too much time on it.

I personally don't allocate time for writing emails, although I typically start and end the day with it. There will always be a few minutes between meetings, or when I'm taking a short break from thinking about math, in which I can write some quick emails. To reduce stress, I do not receive work emails on my phone and have turned off most notifications, so that I only see emails when I actively choose to do so. But strangely, it is less stressful for me to check my emails regularly, even outside of working hours, so that I know they are not secretly piling up.

\section{COVID Craziness}

All of the above applies at any time. But we live in exceptional times, and this is reflected in how we manage our time. You may be mourning-if not losing someone or something specific, then at least a sense of normality. You may be very distracted by everything that is going on.

I think we should accept that we may have less energy or mental bandwidth than usual, and simply plan to do less. Now that everything is all online, a lot of idle time has been cut out of our schedules, but we need this time to not overexhaust ourselves rather than squeezing in yet more work. It helps me to work standing some of the time, to keep my body active. I also balance my extra screentime with completely different things (socializing, sports, music, reading).

Listen to your body and cut yourself some slack. If you are working too much, "because there is nothing else to do," maybe the solution is to plan more non-work things that you then commit to. (I have put "sitting on the couch" on daily to-do lists, to make sure it actually happens.) If you feel like

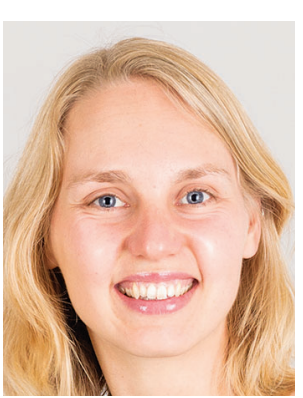

Valentijn Karemaker you are trying and failing to do something, take a break and do something else. While going on a nice walk, you may just suddenly have a great idea. If not, then at least you will have taken a nice walk.

\section{Credits}

Author photo is courtesy of Pasfoto Utrecht Centrum.

\section{How I Learned to Research Like the Incredible Hulk (or I'm Always Angry)}

\section{Robert W. Vallin}

In the early 1990s, jobs were difficult to find, and my job search was torturous. I answered more than 100 ads, went to the 1992 Joint Mathematics Meetings (that year in Baltimore, MD) as a freshly-minted $\mathrm{PhD}$, and participated in the cattle call known as the Employment Center. And then I waited, and waited, and waited. My first on-campus interview was in April. But the fates were kinder to me than others. In August, I was bright-eyed, bushy-tailed, and starting a tenure-track job. I landed at what seemed like a good, if not great, school for me-a mid-level state school with a four-four teaching load and "professional development" rather than research expectations.

I was okay with the teaching load, despite its heaviness. Service would work out-I had been involved in lots of service as an undergraduate and graduate student. But there was the third part. I did not have to do research per se, but I wanted to do it. Since the first time I figured something out that had never been figured out before and then saw my name in print, I wanted to do it again. I wanted to be like my thesis advisor and the bigwigs he knew. But how? Yes, I had written a thesis and published it as two papers. However, my results had come from meeting with my thesis advisor, having him suggest the path I should look at for the next week, and seeing him the following Monday. Lather, rinse, and repeat. Now I was on my own. To make a long story short, I decided I wanted to move away from my thesis (but still do research in real analysis), and so I started looking through journals for something that interested me. What I did not realize was that my thesis was not just guided research, but pretty heavily-guided research. Working on my own was going to be hard.

It's been long enough that I don't remember the topic, but I do remember trying to find some results and thinking I had some small, but clever ideas. In my naive state, I thought that even a small thing, whether a positive proof or a negative example, would be interesting and publishable. I was one of the first in my department to get a desktop computer and one of only two who knew LaTeX and could typeset mathematics to look nice. So, I typed up my results

Robert W. Vallin is a professor of mathematics at Lamar University. His email address is robert.va17in@1amar.edu.

This excerpt is reprinted from Living Proof: Stories of Resilience Along the Mathematical Journey, co-published by AMS and MAA, 2019. Available for free download from https://bookstore.ams.org//vngproof and from https://www. maa.org/LivingProof.

DOI: https://dx.doi.org/10.1090/noti2275 